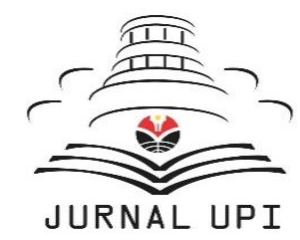

INDONESIAN JOURNAL OF APPLIED LINGUISTICS

Vol. 10 No. 1, May 2020, pp. 184-193

Available online at:

https://ejournal.upi.edu/index.php/IJAL/article/view/25034

https://doi.org/10.17509/ijal.v10i1.25034

\title{
Problems following topic shift in interactions with repaired cleft children
}

\author{
Mohammad Azannee Saad ${ }^{1 *}$, Jariah Mohd Jan ${ }^{2}$ and Ridwan Wahid ${ }^{2}$ \\ ${ }^{1}$ Kulliyyah of Education, International Islamic University Malaysia, 53100 Gombak Selangor, Malaysia \\ ${ }^{2}$ Faculty of Languages and Linguistics, University of Malaya, 50603 Kuala Lumpur, Malaysia
}

\begin{abstract}
Children with a history of cleft lip and/or palate (CL/P) can experience a range of difficulties such as sound articulation errors and reduced psychosocial functioning. This causes interaction with them to contain more frequent communication breakdowns than non-cleft children. The present study shows evidence of such breakdowns involving topic shifts in the interaction between parents and their repaired CL/P children. Interactional data were obtained through a series of recordings of three parent-child sets. The process is guided by the framework of Conversation Analysis (CA) while coding of topic shift adopts Crow's typology (1983). Findings show that topic shift during interaction can indeed cause problems for children with a history of cleft, especially involving palatal cleft. Specifically, through the children's repair initiations, the problems are manifest when a topic is introduced once the previous topic concludes, when a topic is extended and when a topic is revisited. This study shows that topic shift can potentially be a source of problems to CL/P children. Findings are useful for speech therapists, parents and teachers.
\end{abstract}

Keywords: Cleft lip and/or palate; communication breakdown; conversation analysis; parentchild interaction; topic shift

First Received:

22 February 2020

Final Proof Received: 21 May 2020
Revised:

28 March 2020

How to cite (in APA style):

Saad, M. A., Jariah, M. J., \& Wahid, R. (2020). Problems following topic shift in interactions with repaired cleft children. Indonesian Journal of Applied Linguistics, 10(1), 184-193. https://doi.org/10.17509/ijal.v10i1.25034

\section{INTRODUCTION}

Cleft lip and/or palate (CL/P) is the most common birth defect around the world (Xiangyou et al., 2019). The occurrence is recorded to generally impact one in every 700 live births worldwide but cleft cases in South-East Asian countries seem to be higher where the prevalence is between 1.1 and 1.9 per 1000 live births (Abumustafa et al., 2019). In Malaysia, its occurrence is recorded at 1.24/1000 births. The causes of cleft are primarily linked to history of cleft in family and/or substances taken by mother during pregnancy. However, definite causes are yet to be determined (Chetpakdeechit, 2010).

Cleft is classified based on the affected areas: cleft lip, cleft palate or cleft lip and palate. Given lip and hard palate are parts of speech mechanism, one negative consequence of cleft is on speech development. Speech of cleft-affected children is characterised into three: audible nasal air escape, hypernasality and weakening of high-pressure consonants such as /p/, /t/ and /k/ (Havstam, 2010). To correct speech outcome, corrective surgery is the immediate treatment plan which later will be followed by other associated treatments such as speech therapy.

However, as surgery will not be performed until babies reach certain level of weight, language delays can be expected. Several studies have documented the deficits in early language development such as delays in expressive vocabularies as well as syntax (Boyce et al., 2018). The usage of vocabularies was found to be poorer when cleft children are compared to normal developing toddlers (Lancaster et al., 2020). Further

\footnotetext{
* Corresponding Author

Email: azannee@iium.edu.my
} 
comparison also showed them to be lacking in consonant inventory and produce significantly more error patterns (Scherer et al., 2012).

With poor early language development skills, children with cleft even after corrective surgery can develop difficulties in psychosocial functioning (De Sousa et al., 2009) and interactional skills (Beluci \& Genaro, 2016). In a broader linguistic term of pragmatics, interactional skills of cleft-affected children are the least area to be investigated due to high attention on pronunciation aspect (Frederickson et al., 2006). However, there is indeed a number of studies focusing on how such children participate in everyday interaction (McGahey, 2004).

One of the early studies is Chapman et al. (1998) that has examined conversational skills of preschool- and school-age children with history of cleft. When they are compared to non-cleft children of similar age, cleft children are found to have lesser assertive profiles; whereby most of their utterances are due to initiation by other speakers. Similarly, Frederickson et al. (2006) found lesser assertive utterances in the speech of younger children with history of cleft than normal developing children. Such children are also identified to be passive speakers.

In a higher age group, Slifer et al. (2004) recorded stimulated interaction of repaired cleft children between the age of 8 and 15 years old. Results in particular have identified their failure to give responses to conversational partners' questions, have limited questions being asked to others and score lower Rho correlation value than non-cleft participants in certain speech acts such as making offer. In addition, parents have also reported them to be socially incompetent. In agreement to Slifer's, Cocquyt et al. (2012) claimed that problems in starting up and participating in conversation are common among cleft children. This is especially true when cleft children are compared to other clinical populations such as autistic and Down syndrome children who exhibit different types of problems.

Overall, findings are consistent to show the deficiency in social interaction among cleftaffected children. Such issue may be derived from poor cognitive functioning that the children are expected to develop. In addition to language and social, cognitive is another important skill for efficient social interaction (Cho \& Larke, 2010). For these children, studies have identified their poorer cognitive functioning across all domains of testing such as processing speed, memory, attention and language (Roberts et al., 2012). As such, one can predict the difficulty for cleft children to participate in social interaction that happens spontaneously and experiences topic change at swift.
Topic is an important element of conversation. Even though the notion has been used to describe several concepts in linguistics (Baker, 2016), topic within the discourse of conversation is commonly defined as the "aboutness" of conversation (Riou, 2015) or something that speakers choose to talk about which then, becomes the content of conversation (Bloch et al., 2015). This understanding hence positions topic to be the "building block" of conversation (Baker, 2016, p. 1).

Riou (2015) characterised topic into three main characteristics; topic becomes the speakers' shared attention, it is not exterior to speakers or interactional setting and it is co-constructed where speakers take turns to make their contributions such as asking questions, commenting or giving responses. With specific reference to the third characteristic, the negotiation through turn-taking system allows topics to have flow and continuation and hence, be developed (Nuri \& Waode, 2017). Topic development also allows conversation to not simply be restricted to one particular topic only. In fact, conversation is claimed to often include many topics (Sharimila Bai \& Kuang, 2018). Some processes that enable topic development include topic continuation, topic shift, topic reintroduction and topic recycling (Gardner, 1987).

It is thus essential for speakers to be equipped with the ability to manage topics properly when topics are many. Existing literatures have documented several linguistic resources that are employed by speakers to indicate change or transition between topics. These include among others words such as "so" (Bolden, 2009), prosodic property (Riou, 2017) and laughter (Bonin et al., 2012). However, topic change can also happen without speakers being specific or using explicit element to inform other speakers on the change. Especially in such case, topic change can bring negative implications to mutual understanding between speakers. Schegloff (1979) showed that if turn containing topic change is not produced with self-repair, it is likely that the next turn will include repair initiation.

Schegloff (1979) has provided evidence that topic change can be one of the reasons for communication breakdown to occur between speakers. For this reason, we can expect the severity of such problem to be higher when conversation involves speakers with specific language disorders. For example, speakers with motor speech problems or dysarthria are seen to encounter problem in conversation when there is transition between topics (Bloch et al., 2015). Similarly, autistic children who are well documented to have social communication deficits have been documented to demonstrate poor topic management skill (Sevlever et al., 2015). Children with language delays also 
exhibit difficulties in topic management during interaction (van Balkom et al., 2010).

Clearly, topic shift is one aspect of conversation that can cause problem for language impaired population (Bloch et al., 2015). In light with this, the present study is conducted to highlight evidences of communication breakdowns found in data of daily interaction between parents and their children with history of CL/P. Specifically, this study attempts to show that when parents execute topic change such as topic extension or initiate new topic, the children would experience problems that are evident in their repair initiation turns. In other words, when there is topic shift in interaction, there is a high a high chance of the next turn by children to be repair initiation turn to indicate their problems.

\section{METHOD}

\section{Research design}

This study intends to highlight communication breakdowns that have occurred following topic shift made by conversational partners in everyday interaction with repaired cleft children. As such, the method of Conversation Analysis (CA) that is primarily qualitative is adopted to guide the data collection procedure and data analysis technique.

\section{Participants}

The primary participants of this study are children with repaired $\mathrm{CL} / \mathrm{P}$ while parents are included to serve as children's conversational partners. Specifically, three parent-child sets were recruited for their everyday interactions to be recorded and analysed. The recruitment of the participants was made through two cleft centres; one is a cleft clinic governed by a university's hospital and the other is a non-profit organisation that caters to cleftaffected families. Selection of participants is restricted to first, language that they use to interact (Malay language and English language) for the purpose of understanding and secondly, children being at primary school age with history of cleft. Other variables such as gender, cleft types or severity level and socio-economic status of the family are not within the scope of this study.

The permission for the family to participate was initially granted by the administrators at the two aforementioned centres. Once the family was informed, parents were explained on the objectives of study, their rights to withdraw and outcomes of the study. Subsequently, children's participation was granted by their respective parents. The formal inclusion was made through parents signing an informed consent letter.

Table 1 provides information on the children's demographic profiles. To preserve anonymity, suitable pseudonyms were used to identify the children while generic descriptions such as father or mother were assigned to the parents.

Table 1

Children's Demographic Profiles

\begin{tabular}{lccc}
\hline Profile & Child 1 & Child 2 & Child 3 \\
\hline Pseudonym & Lisa & Aiman & Aniq \\
Recruitment age & 7 years old & 9 years old & 11 years old \\
Recording ages & $7 \&$ years old & $9 \& 10$ years old & 11 \& 12 years old \\
Gender & Female & Male & Male \\
Types of cleft & Unilateral CL & Bilateral CP & Unilateral CLP \\
Cleft surgery & Yes (one time) & Yes (multiple) & Yes (multiple) \\
Speech therapy & No & Yes & Yes \\
\hline
\end{tabular}

\section{Data}

Data for this study are part of a large data set that specifically look into the practice of other-initiated repair, an interactional practice whereby one speaker initiates repair following trouble relating to speaking, hearing or understanding in the speech of another speaker. The data primarily consist of everyday interaction in Colloquial Malay, a loose version of Standard Malay language that is common to be used in informal interaction. Certain parts of the interaction contain instances of the participants speaking in English or code-switching between the two languages. However, data in English language can generally be viewed as minimal.

\section{Data collection procedure}

This study is principally guided by the framework of CA. CA is a scientific study that investigates how actions are accomplished through interaction (Wilkinson, 2009). It emerged from the work of Harvey Sacks, Emanuel Schegloff and Gail Jefferson in the $1960 \mathrm{~s}$ and is part of ethnomethodological work. In obtaining its data, CA focuses on everyday interaction between people that is deemed to be natural. The interaction will be recorded and later transcribed for the purpose of analysis.

As such, this study first arranged time with recruited participants for their interactions to be recorded. Participants freely decide on aspects that matter to the interactions such as time and place of recording in order to preserve their comfort. Once logistic arrangement is finalised, recording process began.

Recordings mostly took place at participants' home except in a number of recordings where 
participant requested to be recorded at other public places such as restaurant. The clarity of recording is maintained even when the recordings were performed at such places. Suitable recording tools were used to record the interaction and were placed near to participants when they interact.

Interactions were not restricted to any specific topic or stimulated activity. Rather, the participants were free to talk about anything. This has resulted the study to have recordings that range from a few minutes of interaction to almost a few hours. Such decision was made to ensure the interactions are at the most natural state. In the end, the study is able to collect almost 7-hour of interactional data.

\section{Transcription}

The recorded interactions were later transcribed to provide static form of verbal data (Liddicoat, 2007). To serve this purpose, The Jefferson System of Transcription Notation (University of Leicester, 2020) has been adopted as reference (see Appendix). This system is preferred because it captures various features of talk in written form such as pauses, overlaps, pitch, sound lengthening and pace of talk. In addition, non-verbal data such as eye gaze or hand movement are also integrated into the transcription. Such techniques thus allow this system to provide comprehensive representation of interactional data.

The interactions were mostly conducted in Malay language. To facilitate understanding, the transcription was prepared in a multi-linear format (Hepburn \& Bolden, 2013). In this format, the first line represents the original talk as in the recording while the second line provides a morpheme-bymorpheme English gloss of the original that gives translation to original word and grammatical information. Finally, the third line represents English translation that aims to take the local and interactional meaning of the original.

\section{Data analysis technique}

The first step in data analysis was identification of sequences within the interactions that contained breakdowns. The identification was made by looking at turns containing clarification requests such as I don't understand or simply huh? that prompted the other speaker responsible for topic shift to provide a repair. Once the sequences were located, turns that were the sources of problems were coded according to model of topic shifts proposed by Crow (1983). According to this model, topic shifts can be grouped into four types; topic initiation, topic shading, topic renewal and topic insertion.

Topic initiation refers to attempts made by a speaker to introduce new topic of interaction either at the beginning of interaction or after previous topic concludes. On the other hand, topic shading refers to a new topic that has been introduced yet relating to the current on-going topic. Next, topic renewal describes a situation in interaction when speakers shift discussion back to previous topic after another topic ends. Finally, topic insertion is when speakers choose not to abandon the last topic hence shift is made within the same turn of speaking.

Following this coding scheme, turn-by-turn examination which is a hallmark of CA was performed with specific emphasis on reasons for problems to occur (the types of topic shifts) and responses made by children to indicate their problems following topic shift turns by the parents.

\section{FINDINGS AND DISCUSSION}

This section presents findings that will demonstrate the problems experienced by children with history of $\mathrm{CL} / \mathrm{P}$ when their conversational partners performed topic shift. Selected extracts from the interactional data are used to highlight the problems and how such problems are displayed by the children.

\section{Problems following topic initiation}

Problems in topic initiation happens when the parents introduce new topic once previous topic concludes. Extract 1 shows one situation between mother (M) and his son, Aiman (AMN). The interaction took place while both of them were having lunch with father $(\mathrm{F})$ being present as well.

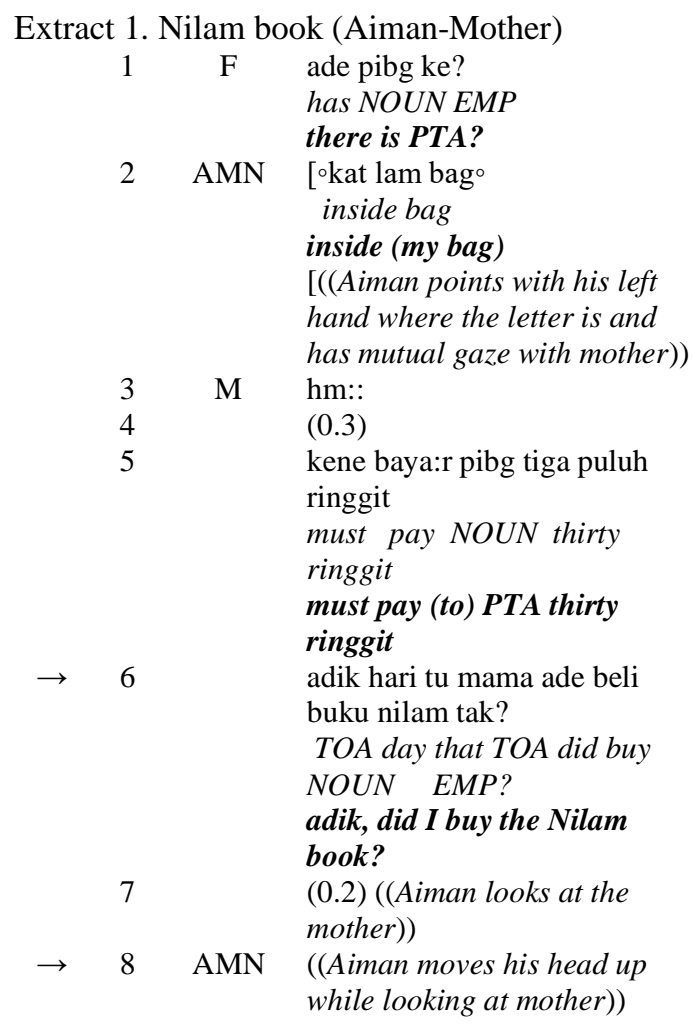


9

M ade: kan buku nilam? ((mother maintains gaze at Aiman)) there EMP NOUN there is Nilam book right?

10 (0.2)((Aiman withdraws mutual gaze)) mama ade beli tak buku nilam? TOA did buy EMP NOUN did I buy the Nilam book?

12 $(0.1)$

13 AMN <ade tige buku> has three books there are three books

*EMP=Emphasis; TOA=Term of address

Extract 1 captures an interaction that primarily includes mother and Aiman with father participated in the earlier part of the sequence. The interaction begins when father seeks confirmation from mother on parent-teacher meeting that is scheduled by Aiman's school (line 1). However, there is an interruption from Aiman when he mentions the invitation letter is in his school bag. Mother acknowledges this through minimal response " $h m$ " (line 3). The use of minimal response by mother seems to bring an end to the sequence and this is evident in 0.3 -second pause that follows.

Mother reclaims the speaking turn and addresses father's earlier confirmation request on PTA (line 5). Even though no specific turn allocation is employed by mother, the utterance which is about payment that parents have to make to school gives indication that she is revisiting the topic from father's previous turn. Immediately after that, mother selects Aiman to be the next speaker (indicated through term of address "adik") and puts forward question that is framed within confirmation request format (line 6). Specifically, she wants to know whether she has bought his school book (Nilam book). The subject that is raised by mother here shows the new topic is introduced (topic initiation) once she concludes topic on PTA with father. However, there is a pause of 0.2 seconds even though Aiman in line 7 establishes mutual gaze with mother to signal his awareness on the allocated turn (Ho et al., 2015). In line 8, Aiman initiates repair from mother through non-verbal strategy (Jariah \& Saad, 2018). He moves his head up to signal the trouble he is having with mother's speech. Such behaviour prompts mother to repair as evident in line 9.

Another example of problem resulting from topic initiation is given in Extract 2. The extract showcases interaction between Aniq (AQ) and his mother (M).

Extract 2. After Friday prayer (Aniq-Mother)

$1 \mathrm{M}$ besok sekolah tak nik? tomorrow school EMP TOA tomorrow is school (day) nik?

$2 \quad$ (0.1) ((mother gazes at Aniq))

\author{
3 AQ sekolah ((Aniq holds handkerchief \\ and plays with it)) \\ school \\ (yes) school \\ $4 \quad$ (0.3) ((mother focuses on her \\ phone)) \\ $\rightarrow \quad 5 \quad$ M hari tu yang jumaat lepas tu pegi \\ jalan kaki?, \\ day that which friday after that go \\ walking \\ that day which is last friday, (you) \\ go (by) walking? \\ $\rightarrow 6$ AQ ojumaa:to= ((Aniq withdraws \\ mutual gaze)) \\ friday \\ friday \\ $7 \mathrm{M} \quad=$ lepas semayang jumaat \\ after pray friday \\ after friday prayer \\ $8 \quad$ (0.1) ((mother maintains gaze at \\ Aniq)) \\ 9 AQ a:: \\ *EMP=Emphasis; TOA=Term of address
}

Extract 2 is part of the on-going interaction between Aniq and his mother where they both are talking on matters related to Aniq's school. Line 1 shows mother's confirmation request from Aniq on one Saturday that has yet to be confirmed whether it will be a school day or not for him. Thus, mother poses tag question to seek confirmation with "tak" being employed as turn completion unit (TCU). Following this request, Aniq appropriately responds by informing that it will be a school day. Consequently, the sequence completes and this is evident when there is a pause in interaction (line 4). Mother is also seen to change her focus to the mobile phone.

In the next line (line 5), mother reclaims the turn of speaking and begins another sequence by asking question. She shows interest on something that has happened last time (how did Aniq go to school last Friday since it was raining) and similarly, this query is framed within the confirmation request format. However, this query poses difficulty to Aniq that could be indicated through withdrawal of mutual gaze (Rossano, 2013). In addition, his response which is a recycle of mother's word (jumaat) that becomes the problem for him is produced with slow volume of speech and slight lengthening of the end sound. Such features indicate his difficulty to give the required response following new topic that has been introduced by mother. Consequently, mother repairs in the subsequent turn (line 7) and Aniq started to become aware on the topic as evident in line 9.

Problems following topic shading

In addition to topic initiation where new topic is introduced, topic shading can also be one point in 
interaction where communication breakdown can occur. Extract 3 shows one example where extension on topic by mother $(\mathrm{M})$ causes a problem to Aniq (AQ).

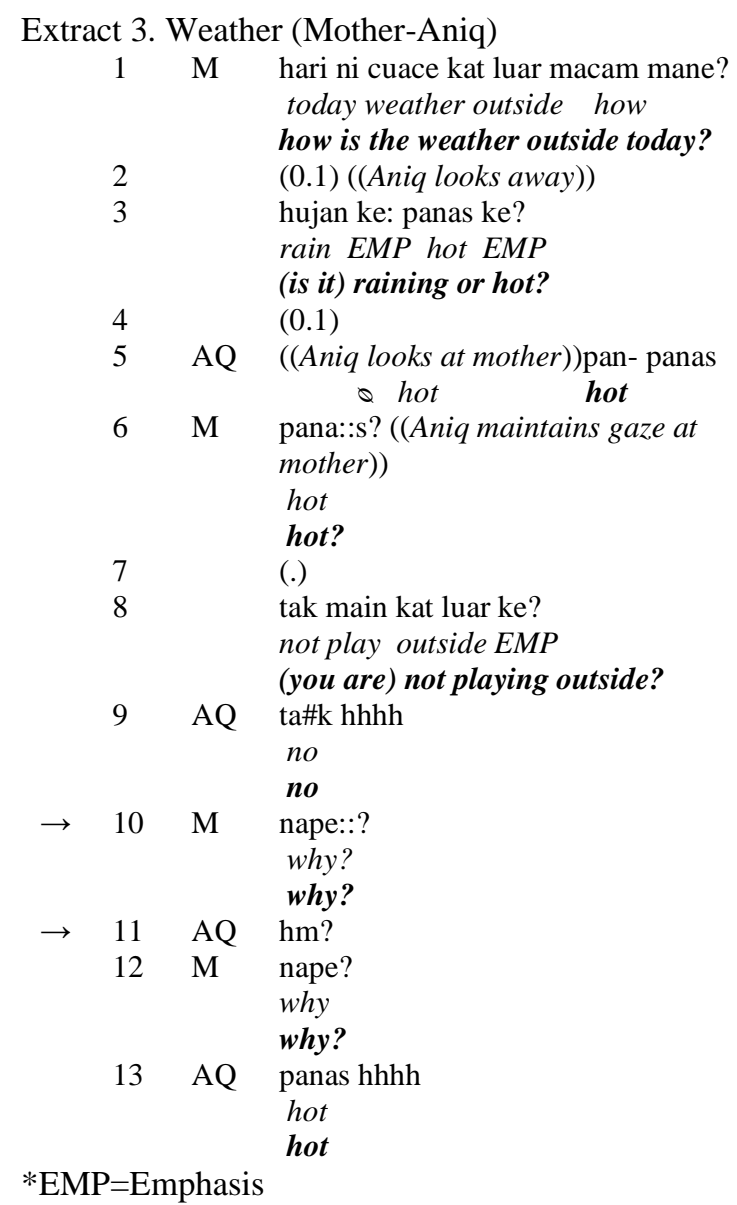

The interaction begins with mother trying to have a casual talk with Aniq. She makes reference to the weather outside and asks Aniq about it (line 1). As there is a short pause and Aniq's withdrawal of mutual gaze when he looks outside, mother continues to claim turn of speaking by presenting possible answers for Aniq to select (line 2). This seems to be successful as Aniq re-establishes mutual gaze with mother and provides his answer (line 5). Mother recycles Aniq's answer and proceeds with another question (line 6-7). The question that seeks information on Aniq plans to play outside later is responded with simple no ("tak") accompanied with exhalation of breath (line 9).

Aniq's dispreference to go outside which seems unusual to mother prompts mother to seek reason for it. Evidently, line 10 shows mother's question with "nape" or "kenapa" (why) that specifically is used to seek reason. However, it fails to bring the required response from Aniq because in line 11, Aniq initiates repair from mother through open-class word " $h m$ " (Drew, 1997). Even though such strategy does not specify the kind of problem Aniq is having (Svennevig, 2008), mother treats it as initiation of repair and hence, repeats the question (line 12).

Extract 4 further shows another example of communication breakdown indicated through repair initiation that is resulted from topic shading. In the extract, Aniq (AQ) is recorded to be in conversation with mother (M) on some issues that he is having at school. One of them is his vision problem in class. Following this, mother suggests it might be due to the glare of the sun. The extract presented here resumes the interaction when mother shows an interest to know whether Aniq's classroom windows have curtains.

Extract 4. Class curtain (Aniq-Mother)

$1 \quad$ M tak de langsir ye ta $\downarrow$ di: kelas tak de langsir?

no curtain EMP just now class

no curtain

there is no curtain right just now, class has no curtain?

2 AQ huhhuh mane ade langsi:r ((Aniq turns gaze to mother)) no curtain

(there is) no curtain

3 M $\uparrow$ kene la kan

must EMP right

must (have) la right

$\rightarrow 4 \quad$ kutip duit kelas tak?

collect money class EMP

(did you) collect class money?

$\rightarrow \quad 5$ AQ a?

6 M kutip duit kelas tak?

collect money class EMP

(did you) collect class money?

$7 \quad$ F $\quad$ suruh mak buat langsir tu

ask TOA do curtain that ask mak (to) do that curtain

*EMP=Emphasis; TOA=Term of address

Line 1 in Extract 4 presents mother's question to Aniq that is designed as a confirmation request. Specifically, mother seems to notice that Aniq's class is not equipped with curtain (the first part of the utterance) and she continued to request for confirmation in the second part of the utterance. In line 2, Aniq responds by affirming to mother that his classroom is not equipped with curtain. This completes the adjacency pair of question-answer and can possibly close the sequence. However, mother continues in line 3 where she suggests that curtain is a must (so problem such as Aniq's blurry vision can be avoided). Following the suggestion, mother poses another question related to the topic but this time, mother extends the topic by asking whether he and his classmates collect money to buy or install curtain (line 4). There is no specific word or cue employed by mother to indicate this shift of topic but the emphasis word "tak" should yield 
close-response from Aniq. Instead, Aniq's problem is evident in the open-class repair initiator word " $a$ ?" (line 5). This clearly indicates his trouble when mother extends the topic of interaction. Consequently, mother performs repair in line 6 before father joins in line 7 .

\section{Problems following topic renewal}

Extract 5 shows interaction between Aniq (AQ) and his parents relating to his examination result i.e. overall class placement. Prior to this sequence, mother (M) and Aniq were discussing the result of one of his friends in a recent national examination before father (F) joins the discussion by asking Aniq about his own placement result.

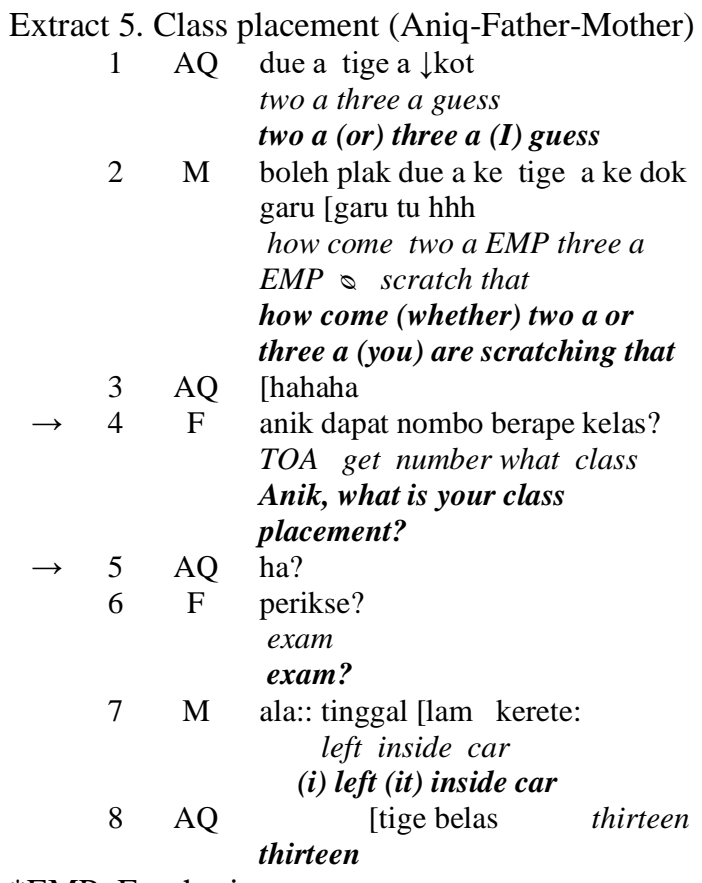

*EMP=Emphasis

Interaction in Extract 5 begins with Aniq's response to mother's earlier query on the examination result of his friend. In line 1, Aniq exhibits uncertainty on the specific result that is evident in the use of "kot" (loosely translated as "guess" as in "I guess so"). He claims his friend has obtained either two As or three As in their recent national examination. Following this, mother changes the focus of interaction by pointing out Aniq's somewhat inappropriate behaviour (Aniq is scratching a part of his body during the interaction) and this invites both of them to laugh.

Father then claims the next turn of speaking (line 4) and asks Aniq question relating to his own class placement. Here, father initiates new topic once mother and Aniq seem to conclude topic about Aniq's friend through their shared laugh (Bonin et al., 2012). In doing so, father specifically allocates turn to Aniq through name calling strategy before proceeding with the question. Upon receiving this question, Aniq claims the speaking turn. However, he is seen to initiate repair through open-class word " $h a$ " in line 5 that evidently displays his problem with father's preceding turn. This immediately prompts father to repair as shown in line 6.

Another example of problem following topic renewal is given in Extract 6. The interaction records multiparty interaction between parents and Aiman (AMN) while they were having lunch. In the interaction, mother $(\mathrm{M})$ first asks Aiman on reason for him to go downstairs (the family lives in an apartment complex). However, the topic is abandoned when father $(\mathrm{F})$ interrupts and seems to create an interaction exclusively with mother on another topic. Once the interaction concludes, mother revisits her earlier query to Aiman. Aiman)

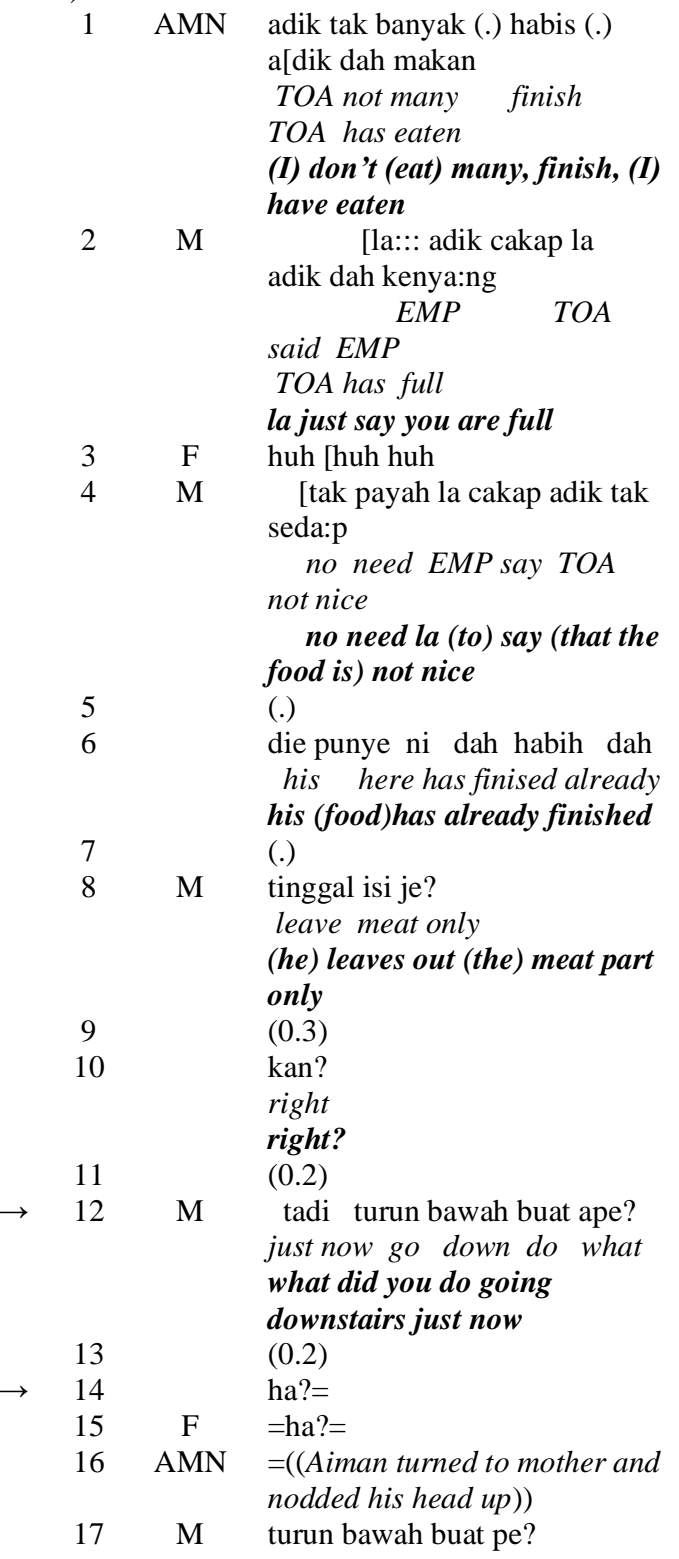


go down do what

what do you do going

downstairs?

$18 \quad(0.2)$

*TOA=Term of address; EMP=Emphasis

The extract presented in Extract 6 begins with Aiman's turn where he somehow informs parents that he has finished his lunch or claims he has eaten certain food being offered to him (line 1). The different kinds of information are evident when there are short pauses in between. Mother then in the next turn (line 2) puts forward suggestion that Aiman has eaten enough (line 2) and rejects Aiman's claim earlier that the food is not nice. Following this, mother shifts the conversation to father when they are talking about the leftover food (line 6 - 10). In line 11, there is a short pause even though in preceding turn (line 10), mother seeks confirmation request. However, the request is ignored by both father and Aiman which explained the pause.

Mother then reclaims turn of speaking and in line 12 , she revisits her query to Aiman on reason for him to go downstairs. As a side note, the question has been asked much earlier but there appears to be an interruption when father introduces new topic that is relevant to him and mother only. In line 12, mother revisits the topic and asks Aiman the same question. The question in line 12 is considered to be specific with question word "buat ape" (do what) is employed but since mother does not specify the next speaker, a short pause occurs (line 13). Line 14 shows mother's effort to reallocate the turn with simple open-class word and here, it is found to be successful because father claims the turn. Aiman also claims the next turn (line 15) but employs a specific head movement to initiate repair from mother; he nods his head up while placing gaze at mother. This specific nonverbal behaviour is treated as repair initiation (Jariah \& Saad, 2018) when mother in line 16 provides repair by repeating her earlier question.

Overall, this study has supported the fact that communication breakdowns are not random and can occur at specific place during the on-going interaction. Specifically, findings have been in agreement with Bloch et al. (2015) that highlights topic shift to be one possible place in interaction where communication breakdowns can occur. In particular, this study has managed to identify problems that have occurred following topic initiation, topic shading and topic renewal in interaction with children with repaired CL/P. Breakdowns following topic insertion on the other hand are not found in the data set.

Failure to become aware on the shift of topics shown by such children can signify their poor cognitive skills. It has been understood that cognitive skills are one of the requirements for effective interaction (Cho \& Larke, 2010). Several existing studies that have focused on examining the cognitive functioning such as remembering, reasoning and paying attention have consistently shown the poorer performance level of the cleftaffected children than the non-cleft population (Hentges et al., 2011; Roberts et al., 2012). Hence, findings from this study further strengthens the relationship between cleft and its impact on their cognitive ability.

Looking at individual children in the aspect of cleft type, it can be noted from the extracts presented in this study that problems following topic shift actually were significantly low in interaction with Child 1, Lisa who has history of cleft lip only (CL). On the contrary, the occurrence of problems is consistent in interactions with Aiman (CP) and Aniq (CLP). The almost non-existence of problems within the context of topic shift in interaction with Lisa may be explained through the fact that children with CL only will not experience greater language deficits or have the same risk similar to children with cleft involving the palate (Vallino et al., 2008). In fact, it is typical within clinical studies to assume the difference in impacts between cleft affecting lip only and cleft affecting the palate as well (Hardin-Jones \& Chapman, 2011). For this particular reason, the comparison between each child in fact has enabled this study to somehow develop possible link between cognitive skills of children with history of cleft and their types of cleft. However, this requires further investigation.

\section{CONCLUSION}

In summary, the present study has provided evidences on problems that occur when topic of interaction shifts. Data that were acquired through recorded interactions between parents and repaired cleft children have shown such occurrences can be expected when topic is initiated, extended (topic shading) or revisited (topic renewal). Poor cognitive skills that have been documented in existing database could potentially be the reason for them to experience such difficulty. This information can be useful for speech-language pathologist to incorporate element of everyday interaction such as topic shift into speech therapy. They can also design activities for parents to adopt when they interact with the children at home which hopefully could further increase their interaction skills. Similarly, teacher when having such children in their classroom can use this information to guide interaction with them.

Future intended studies are recommended to increase the interactional data especially involving children with cleft lip only to further validate the claim made through this study. It is also 
recommended for future studies to conduct analysis on linguistic resources employed by parents in constructing turn that cause topic shift to be problematic or unproblematic.

\section{REFERENCES}

Abumustafa, A., Alkhen, B., \& Tolarova, M. M. (Eds.). (2019). Proceedings of the $21^{\text {st }}$ Annual Pacific Excellence Day. Dugoni School of Dentistry.

https://scholarlycommons.pacific.edu/excellenc e-day/2019/events/19/

Baker, K. K. (2016). Topic manipulation in five children with language impairment in response to topic probes [Unpublished master's thesis]. Brigham Young University.

Beluci, M. L., \& Genaro, K. F. (2016). Quality of life of individuals with cleft lip and palate pre- and post-surgical correction of dentofacial deformity. Journal of School of Nursing, 50(2), 216-221. https://doi.org/10.1590/S0080623420160000200006

Bloch, S., Saldert, C., \& Ferm, U. (2015). Problematic topic transitions in dysarthric conversation. International Journal of SpeechLanguage Pathology, 17(4), 373-383. https://doi.org/10.3109/17549507.2014.979879

Bolden, G. B. (2009). Implementing incipient actions: The discourse marker 'so' in English conversation. Journal of Pragmatics, 41(5), 974-998. https://doi.org/10.1016/j.pragma.2008.10.004

Bonin, F., Campbell, N., \& Vogel, C. (Eds.). (2012). Proceedings of the IEEE $3^{\text {rd }}$ International Conference on Cognitive Infocommunications. Institute of Electrical and Electronics Engineers. https://ieeexplore.ieee.org/document/6422056

Boyce, J. O., Kilpatrick, N., \& Morgan, A. T. (2018). Speech and language characteristics in individuals with nonsyndromic submucous cleft palate: A systematic review. Child: Care, Health and Development, 44(6), 818-831. https://doi.org/10.1111/cch.12613

Chapman, K. L., Graham, K. T., Gooch, J., \& Visconti, C. (1998). Conversational skills of preschool and school-age children with cleft lip and palate. The Cleft Palate-Craniofacial Journal, 35(6), 503-516. https://doi.org/10.1597/15451569_1998_035_0503_csopas_2.3.co_2

Chetpakdeechit, W. (2010). Subjective and objective aspects on living with a cleft. A study focused on the isolated cleft palate and the total bilateral cleft lip and palate [Unpublished doctoral dissertation]. University of Gothenburg.

Cho, E. H., \& Larke, P. J. (2010). Repair strategies usage of primary elementary ESL students: Implications for ESL teachers. The Electronic Journal for English as Second Language, 14(3),
1-18. https://www.tesl-

ej.org/wordpress/issues/volume14/ej55/ej55a4/

Cocquyt, M., Zink, I., Mommaerts, M., Nadjmi, N., \& Derwart, H. (Eds.). (2012). Proceedings of the $8^{\text {th }}$ CPLOL Congress. CPLOL.

Crow, B. K. (1983). Topic shifts in couples' conversations. In R. T. Craig \& K. Tracy (Eds.), Conversational coherence: Form, structure and strategy (pp. 136-156). Sage Publications.

De Sousa, A., Devare, S., \& Ghanshani, J. (2009). Psychological issues in cleft lip and cleft palate. Journal of Indian Association of Pediatric Surgeons, 14(2), 55-58. https://doi.org/10.4103\%2F0971-9261.55152

Drew, P. (1997). 'Open' class repair initiators in response to sequential sources of trouble in conversation. Journal of Pragmatics, 28(1), 69101. https://doi.org/10.1016/S03782166(97)89759-7

Frederickson, M. S., Chapman, K. L., \& HardinJones, M. (2006). Conversational skills of children with cleft lip and palate: A replication and extension. The Cleft Palate-Craniofacial Journal, 43(2), 179-188. https://doi.org/10.1597/04-086.1

Gardner, R. (1987). The identification and role of topic in spoken interaction. Semiotica, 65(2), 129-141. https://doi.org/10.1515/semi.1987.65.1-2.129

Hardin-Jones, M., \& Chapman, K. (2011). Cognitive and language issues associated with cleft lip and palate. Seminars in Speech Language, 32(2), 127-140. https://doi.org/10.1055/s-00311277715

Havstam, C. (2010). Attitude to speech and communication in individuals born with cleft lip and palate [Unpublished doctoral dissertation]. University of Gothenburg.

Hentges, F., Hill, J., Bishop, D. V., Goodacre, T., Moss, T., \& Murray, L. (2011). The effect of cleft lip on cognitive development in schoolaged children: A paradigm for examining sensitive period effects. Journal of Child Psychology and Psychiatry and Allied Disciplines, 52(6), 704-712. https://doi.org/10.1111/j.14697610.2011.02375.x

Hepburn, A., \& Bolden, G. B. (2013). The conversation analysis approach to transcription. In J. Sidnell \& T. Stivers (Eds.), The handbook of conversation analysis (pp. 1-21). Blackwell Publishing.

Ho, S., Foulsham, T., \& Kingstone, A. (2015). Speaking and listening with the eyes: Gaze signaling during dyadic interactions. PloS One, 10(8).

https://doi.org/10.1371/journal.pone.0136905

Jariah, M. J., \& Saad, M. A. (2018). Repair initiation strategies in everyday interaction by speakers of Malay language. Journal of Language and Communication, 5(2), 211-224. 
http://journalfbmk.upm.edu.my/index.php/jlc/ar ticle/view/27/24

Lancaster, H. S., Lien, K. M., Chow, J. C., Frey, J. R., Scherer, N. J., \& Kaiser, A. P. (2020). Early speech and language development in children with nonsyndromic cleft lip and/or palate: A meta-analysis. Journal of Speech, Language and Hearing Research, 63(1), 14-31. https://doi.org/10.1044/2019_JSLHR-19-00162

Liddicoat, A. J. (2007). An introduction to conversation analysis. Continuum.

McGahey, H. J. (2004). Early speech and language development: A comparison of typically developing children to children with cleft palate [Unpublished master's thesis]. East Tennessee State University.

Nuri, S., \& Waode, H. (2017). A study of turn-taking used in radio talk show under the topic "gender equality and women's empowerement". TELL Journal, 5(2), 60-70. http://doi.org/10.30651/tell.v5i2.320

Riou, M. (2015). A methodology for the identification of topic transitions in interaction. Discours, 16(1), 3-28. https://doi.org/10.4000/discours.8997

Riou, M. (2017). The prosody of topic transition in interaction: Pitch register variations. Language and Speech, 60(4), 658-678. https://doi.org/10.1177/0023830917696337

Roberts, R. M., Mathias, J. L., \& Wheaton, P. (2012). Cognitive functioning in children and adults with nonsyndromal cleft lip and/or palate: A meta-analysis. Journal of Pediatric Psychology, 37(7), 786-792. https://doi.org/10.1093/jpepsy/jss052

Rossano, F. (2013). Sequence organisation and timing of bonobo mother-infant interactions. Interaction Studies, 14(2), 160-189. https://doi.org/10.1075/is.14.2.02ros

Schegloff, E. A. (1979). The relevance of repair to syntax-for-conversation. In T. Givon (Ed.), Syntax and semantics volume 12 (pp. 261-286). Academic Press.

Scherer, N. J., Williams, L., Stoel-Gammon, C., \& Kaiser, A. (2012). Assessment of single-word production for children under three years of age: Comparison of children with and without cleft palate. International Journal of Otolaryngology, 1-8. https://doi.org/10.1155\%2F2012\%2F724214

Sharimila Bai, P. S., \& Kuang, C. H. (2018). Topic shifts in conversations: Focus on Malaysian Chinese teenagers. Sarjana, 26(2), 101-118. https://ejournal.um.edu.my/index.php/SARJAN A/article/view/10472/7434

Slifer, K. J., Amari, A., Diver, T., Hilley, L., Beck, M., Kane, A., \& McDonnell, S. (2004). Social interaction patterns of children and adolescents with and without oral clefts during a videotaped analogue social encounter. The Cleft Palate-
Craniofacial Journal, 41(2), 175-184. https://doi.org/10.1597/02-084

Sevlever, M., Jennifer, M. G., \& Ferguson, B. (2015). Improving conversational skills in children with autism spectrum disorders: A pilot study of the teaching interaction procedure. International Journal of School and Cognitive Psychology, 1(6), 1-8. https://doi.org/10.4172/24699837.S1-006

Svennevig, J. (2008). Trying the easiest solution first in other-initiation of repair. Journal of Pragmatics, 40(2), 333-348. https://doi.org/10.1016/j.pragma.2007.11.007

University of Leicester. (2020). What is The Jefferson Transcription System? Retrieved from https://www2.le.ac.uk/departments/psych ology/research/child-mental-health/cara1/faqs/jefferson

Vallino, L. D., Zuker, R., \& Napoli, J. A. (2008). A study of speech, language, hearing and dentition in children with cleft lip only. The Cleft PalateCraniofacial Journal, 45(5), 485-494. https://doi.org/10.1597/06-207.1

van Balkom, H., Verhoeven, L., \& van Weerdenburg, M. (2010). Conversational behaviour of children with developmental language delay and their caretakers. International Journal of Language \& Communication Disorders, 45(3), 295-319. https://doi.org/10.3109/13682820902994226

Wilkinson, R. (2009). Conversation analysis and communication disorders. In M. J. Ball, M. R. Perkins, N. Muller \& S. Howard (Eds.), The handbook of clinical linguistics. Blackwell Publishing.

Xiangyou, Y., Hanyao, H., Xing, Y., Bing, S., \& Jingtao, L. (2019). Functional stability analyses of maxillofacial skeleton bearing cleft deformities. Scientific Report, 9(1), 1-10. https://doi.org/10.1038/s41598-019-40478-w

\section{APPENDIX}

Transcription Symbols (adapted from Jefferson Transcription Notations):

(.) a micropause - a pause of no significant length

(0.7) a timed pause - long enough to indicate time

[ ] overlapping speech

$>\quad$ the pace of speech has quickened

$<>\quad$ the pace of speech has slowed down

( ) unclear section

(( )) an entry requiring comment but without a symbol to explain it

Underline a raise in volume or emphasis

$\uparrow \quad$ rise in intonation

$\downarrow \quad$ drop in intonation 